\title{
Moderate-Intensity Swimming Exercises Decrease Body Weight and Lee's Obesity Index in Female Mice (Mus musculus)
}

\author{
Muhamad Fauzi Antoni ${ }^{\mathrm{a}}$, Purwo Sri Rejeki ${ }^{\mathrm{ab}}{ }^{*}$, Sulistiawatic ${ }^{\mathrm{c}}$, Adi Pranoto ${ }^{\mathrm{d}}$, Sugiharto ${ }^{\mathrm{e}}$ \\ *Corresponding Author: purwo-s-r@fk.unair.ac.id \\ a. Sport Health Science, Faculty of Medicine, Universitas Airlangga, Surabaya, Indonesia \\ b. Physiology Division, Department of Physiology and Medical Biochemistry, Faculty of Medicine, Universitas Airlangga, Surabaya, \\ Indonesia \\ c. Department of Public Health, Faculty of Medicine, Universitas Airlangga, Surabaya, Indonesia \\ d. Doctoral Program of Medical Science, Faculty of Medicine, Universitas Airlangga, Surabaya, Indonesia \\ e. Department of Sport Science, Faculty of Sport Science, Universitas Negeri Malang, Malang, Indonesia
}

\begin{abstract}
This study aims to analyze the effect of moderate-intensity swimming exercise which performed in the morning and at night on reducing body weight and Lee's obesity index in female mice (Mus musculus). This study used the true experiment method with the randomized control group post-test-only design. A total of 30 female mice (Mus musculus) at 3 months of age, and weighing 30 - 40 grams (Lee's Obesity Index Value > 0.3) were divided randomly into three groups of 10, namely CTRL (n $=10$, control without intervention), MISEM ( $\mathrm{n}=10$, moderate-intensity swimming exercise in the morning), and MISEN ( $\mathrm{n}$ $=10$, moderate-intensity swimming exercise at night). Body weight and Lee's obesity index was measured twice, namely preexercise and 4 weeks post-exercise. Then, data was analyzed using the Paired Samples T-Test with the Statistical Package for the Social Sciences SPSS version 21 software. The results show that the average body weight on CTRL between pre-exercise vs. post-exercise (33.60 \pm 2.17 vs. $39.20 \pm 3.82 \mathrm{gr}$ (p-values=0.001)), MISEM (33.90 \pm 2.33 vs. $30.70 \pm 3.53 \mathrm{gr}$ ( $\mathrm{p}$-values=0.011)), and MISEN (33.40 \pm 3.47 vs. $26.00 \pm 2.26$ gr (p-values $=0.000)$ ). Lee's average obesity index on CTRL between pre-exercise vs. post-exercise $(0.39 \pm 0.02$ vs. $0.44 \pm 0.02 \mathrm{gr} / \mathrm{mm}$ (p-values $=0.000))$, MISEM $(0.40 \pm 0.02 \mathrm{vs} .0 .42 \pm 0.01 \mathrm{gr} / \mathrm{mm}(\mathrm{p}$-values $=0.000))$, MISEN $(0.41 \pm 0.01$ vs. $0.37 \pm 0.02 \mathrm{gr} / \mathrm{mm}$ (p-values=0.002)). Based on the results of the study, it was concluded that moderateintensity swimming exercise in the night was more effective in reducing body weight and Lee's obesity index than moderateintensity swimming exercise in the morning and control without intervention.
\end{abstract}

Keyword: Obesity, morning exercise, night exercise, body weight, lee's obesity index

\section{Introduction}

Nowadays, obesity has been recognized as a global health problem (Houdebine et al., 2019), because it can adversely affect almost all physiological functions of the body and also becomes a significant public health threat (Chooi et al., 2019). Obesity can increase the risk of various disease conditions, such as diabetes mellitus (Singh et al., 2013), cardiovascular disease (Singh et al., 2013; Czernichow et al., 2011), certain types of cancer (LaubySecretan et al., 2016), various musculoskeletal disorders (Anandacoomarasamy et al., 2008), and poor mental health (Anstey et al., 2011), all of which have negative effects on quality of life, work productivity, and rising healthcare costs (Chooi et al., 2019).

Proper physical exercise not only has an impact on changes in body shape and physical fitness, but also prevent and treat several diseases, including cancer (Jakicic et al., 2018; Hojman et al., 2018; Hansen et al., 2018; Zanuso et al., 2017; Zhang et al., 2016; McKeough et al., 2016; Adamson et al., 2015). In addition, conduct physical exercise regularly also plays an important role in reducing obesity by increasing energy output (Houdebine et al., 2019). Although many therapies and medications have been developed to treat most diseases, 
physical exercise remains a natural alternative and a convenient, safe, and affordable treatment method for the community (Hjorth \& Febbraio, 2018; Lü et al., 2016; Bouchard et al., 2015).

Today, there are many choice of physical exercise, such as brisk walking, running, swimming, cycling, football, and weightlifting (Guo et al., 2020). Differences in physical exercise parameters, such as frequency, intensity, type, and time, can influence the effect of physical exercise on prevention or treatment of disease (Driediger et al., 2018). For example, vigorous-intensity jogging for 6 months significantly reduced body weight, waist circumference, body fat, and blood pressure in patients with obesity and Non-alcoholic Fatty Liver Disease (NAFLD), whereas moderate-intensity physical exercise had no such effect (Zhang et al., 2016).

Recently, several reviewers have summarized the benefits of different types of physical exercise on several diseases, such as Alzheimer's disease (AD), stroke, Parkinson's disease (PD), and Huntington's disease (HD) (Shepherd et al., 2018; Crozier et al., 2018; Mo et al., 2016; Patten et al., 2015; Mo et al., 2015). However, there was still limited study about the diseases and types of physical exercise, and only a few reviews include the benefits to improve some physiological functions of the body (Febbraio, 2017; Overall et al., 2016; Kostrzewa \& Kas, 2014; Hatchard et al., 2014). Thus, it is needed to review thoroughly regarding the benefits of various physical exercise protocols in treating disease and improving physiological functions of the body (Guo et al., 2020). Based on this issue, the purpose of this study was to analyze the effect of moderate-intensity swimming exercise in the morning and at night on reducing body weight and the Lee's obesity index in female mice (Mus musculus).

\section{Materials and Methods}

\subsection{Experimental design}

This research is a true experiment with the randomized control group post-test-only design. A total of 30 female mice (Mus musculus) at 3 months age, and weighing 30-40 grams (Lee's Index Value $>0.3$ ) were divided randomly into three groups of 10 , namely CTRL ( $n=10$, control without intervention), MISEM ( $n=10$, moderateintensity swimming exercise in the morning), and $\operatorname{MISEN}(\mathrm{n}=10$, moderate-intensity swimming exercise in the night). Mice (Mus musculus) were placed in temperature-controlled steel cages $\left(20-22{ }^{\circ} \mathrm{C}, 55-65 \%\right.$ humidity) with a 12-h light/dark cycle (Haslan et al., 2021). This research has followed animal welfare principles published by the European Convention for the Protection of Vertebrate Animals. All research procedures have been approved by the Health Research Ethics Commission, Faculty of Medicine, Airlangga University Surabaya.

\subsection{Protocol of exercise}

Swimming exercises were carried out 3 times in a week for 4 weeks with an intensity of $6 \%$ of body weight and the duration was $70 \%$ of maximum time (Prasetya et al., 2018). Morning swimming exercise was held at 08.00-09.00 AM, while night swimming exercise was held at 20.00-21.00 PM (Pranoto et al., 2020; Kwak et al., 2020). The mice were given intervention of moderate-intensity swimming exercise in the morning and at night, with water temperature maintained at $30 \pm 2{ }^{\circ} \mathrm{C}$ (Wierzba et al., 2006).

\subsection{Data collection}

Body Weight measurements were carried out pre-exercise and post-exercise for 4 weeks using a digital Harnic HL-3650 Heles Scale (0-5kg scale) (Widiatmaja et al., 2021; Rejeki et al., 2021). Meanwhile, Lee's obesity 
index for each mice was measured by dividing the cube root of the body weight (gr) by the naso-anal length $\left(\mathrm{cm}^{2}\right)$ and multiplying the whole expression by 10,000 (Haslan et al., 2021).

\subsection{Statistical analysis}

Statistical analysis was conducted using Statistical Package for the Social Sciences (SPSS) software version 21 (SPSS Inc., Chicago, IL, USA). The researcher used Shapiro-Wilk test for normality, while Levene test for homogeneity test. The difference was analyzed by using Paired Samples T-Test, One-Way ANOVA, followed by Tukey's Honestly Significant Difference (HSD) post-hoc test. All data are presented with Mean \pm Standard Deviation (SD). All statistical analyzes used a significance level $(\mathrm{p} \leq 0.05)$.

\section{Results}

The analysis results of the average body weight pre-exercise vs. post-exercise and average results of Lee's obesity index pre-exercise vs. post-exercise in each group is presented in Figure 1 and Figure 2.

CTRL

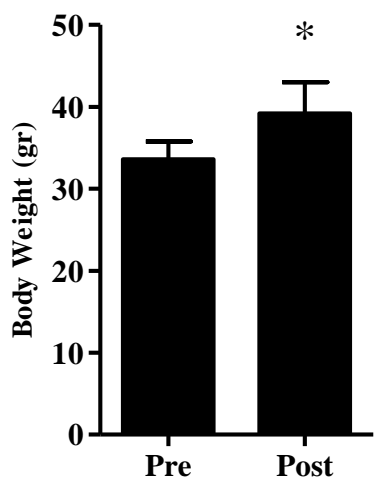

MISEM

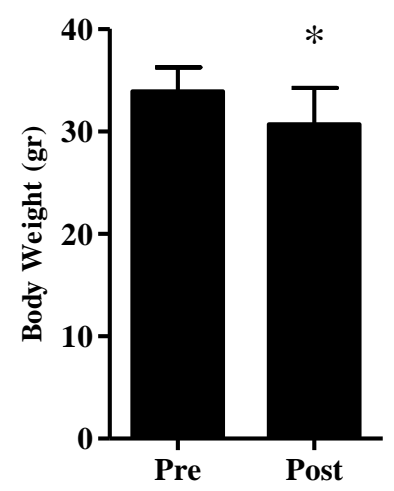

MISEN

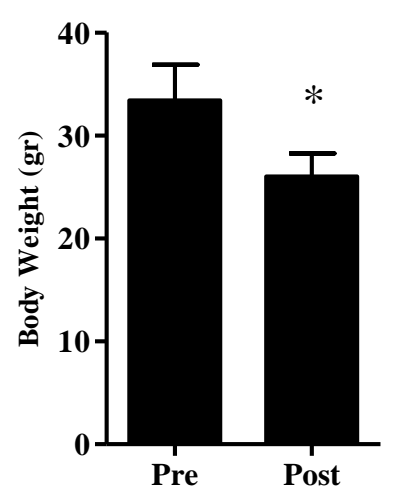

Fig. 1. Average body weight pre-exercise vs. post-exercise in each group

Note: CTRL: control without intervention; MISEM: moderate-intensity swimming exercise in the morning; MISEN: moderate-intensity swimming exercise in the night. Body weight data were presented as average of Mean with Standard Deviation (SD). Significant was considered with $\mathrm{p} \leq 0.05$. $(*)$ significant vs pre-exercise $(\mathrm{p} \leq 0.05)$.

Figure 1 shows that there is an increase in the average body weight between pre-exercise and post-exercise on CTRL, while MISEM and MISEN show a decrease in body weight between pre-exercise and post-exercise. The results of the Paired Samples T-Test analysis on CTRL showed that there was a significant difference in the average increase in body weight between pre-exercise vs. post-exercise (33.60 \pm 2.17 vs. $39.20 \pm 3.82$ gr (pvalues $=0.001)$ ), while the results of the Paired Samples T-Test analysis on MISEM showed a decrease in body weight between pre-exercise vs. post-exercise $(33.90 \pm 2.33$ vs. $30.70 \pm 3.53 \mathrm{gr}$ (p-values=0.011)). Likewise, the results of the Paired Samples T-Test analysis at MISEN also showed a decrease in body weight between preexercise vs. post-exercise $(33.40 \pm 3.47$ vs. $26.00 \pm 2.26 \mathrm{gr}$ ( $\mathrm{p}$-values $=0.000)$ ). 
CTRL

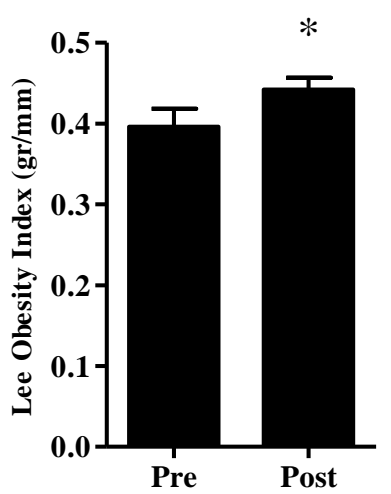

MISEM

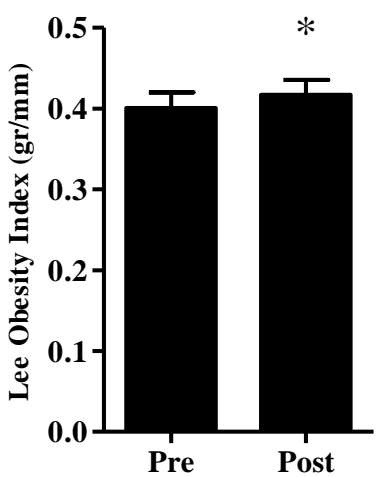

MISEN

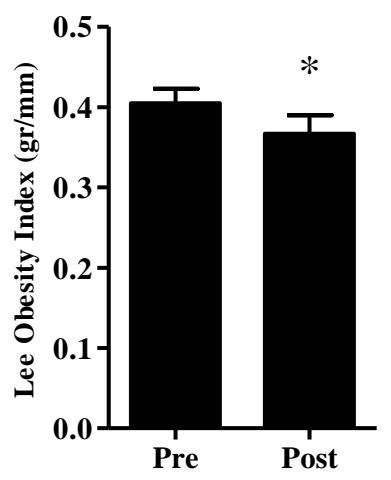

Fig. 2. Average Lee's obesity index pre-exercise vs. post-exercise in each group

Note: CTRL: control without intervention; MISEM: moderate-intensity swimming exercise in the morning; MISEN: moderate-intensity swimming exercise in the night. Lee's obesity index data were presented as average of Mean with Standard Deviation (SD). Significant was considered with $\mathrm{p} \leq 0.05$. (*) significant vs pre-exercise $(\mathrm{p} \leq 0.05)$.

Based on Figure 2, it shows that there is an average increase in Lee's obesity index between pre-exercise and post-exercise on CTRL and MISEM, while MISEN shows a decrease in Lee's obesity index between pre-exercise and post-exercise. The Paired Samples T-Test analysis on CTRL showed that there was a significant difference in increasing Lee's obesity index between pre-exercise vs. post-exercise $(0.39 \pm 0.02$ vs. $0.44 \pm 0.02 \mathrm{gr} / \mathrm{mm}$ (pvalues=0.000)). Likewise, the results of Paired Samples T-Test analysis on MISEM also showed an increase in Lee's obesity index between pre-exercise vs. post-exercise $(0.40 \pm 0.02 \mathrm{vs}$. $0.42 \pm 0.01 \mathrm{gr} / \mathrm{mm}$ (p-values=0.000)). While, the results of the Paired Samples T-Test analysis on MISEN showed a decrease in Lee's obesity index between pre-exercise vs. post-exercise $(0.41 \pm 0.01$ vs. $0.37 \pm 0.02 \mathrm{gr} / \mathrm{mm}$ (p-values $=0.002))$. The analysis results of body weight and Lee's obesity index based on time in each group are presented in Table 1.

Table 1. The analysis results of body weight and Lee's obesity index based on time in each group

\begin{tabular}{|c|c|c|c|}
\hline Group & Time & Mean \pm SD & p-values \\
\hline \multicolumn{4}{|c|}{ Body Weight (gr) } \\
\hline CTRL & & $33.60 \pm 2.17$ & \\
\hline MISEM & Pre-exercise & $33.90 \pm 2.33$ & 0.918 \\
\hline MISEN & & $33.40 \pm 3.47$ & \\
\hline CTRL & & $39.20 \pm 3.82$ & \\
\hline MISEM & Post-exercise & $30.70 \pm 3.53^{*}$ & 0.000 \\
\hline MISEN & & $26.00 \pm 2.26 * \dagger$ & \\
\hline CTRL & & $5.60 \pm 3.53$ & \\
\hline MISEM & $\operatorname{Delta}(\Delta)$ & $-3.20 \pm 3.19 *$ & 0.000 \\
\hline MISEN & & $-7.40 \pm 4.38 * \dagger$ & \\
\hline \multicolumn{4}{|c|}{ Lee's obesity index (gr/mm) } \\
\hline CTRL & & $0.39 \pm 0.02$ & \\
\hline MISEM & Pre-exercise & $0.40 \pm 0.02$ & 0.601 \\
\hline MISEN & & $0.41 \pm 0.01$ & \\
\hline CTRL & & $0.44 \pm 0.02$ & \\
\hline MISEM & Post-exercise & $0.42 \pm 0.01 *$ & 0.000 \\
\hline MISEN & & $0.37 \pm 0.02 * \dagger$ & \\
\hline CTRL & & $0.05 \pm 0.02$ & \\
\hline MISEM & $\operatorname{Delta}(\Delta)$ & $0.01 \pm 0.01 *$ & 0.000 \\
\hline MISEN & & $-0.04 \pm 0.03 * \dagger$ & \\
\hline
\end{tabular}

Note: Body weight and Lee's obesity index data were presented as average of Mean with Standard Deviation (SD). Significant was considered with $\mathrm{p} \leq 0.05$. $(\dagger)$ significant vs MISEM $(\mathrm{p} \leq 0.05)$, and $(*)$ significant vs CTRL $(\mathrm{p} \leq 0.001)$. 
Based on Table 1, the One-Way ANOVA test showed that there was no significant difference in mean body weight pre-exercise in all groups $(\mathrm{p} \geq 0.05)$, while 4 weeks post-exercise and delta $(\Delta)$ showed significant differences in mean body weight in all groups $(\mathrm{p} \leq 0.001)$. The results of Tukey's HSD post-hoc test showed that there was a significant difference in the average decrease in body weight at 4 weeks post-exercise between MISEM and CTRL ( $\mathrm{p}=0.000)$, MISEN and CTRL ( $\mathrm{p}=0.000)$, and MISEN and MISEM ( $\mathrm{p}=0.009)$. The results of the Tukey's HSD post-hoc test showed that there was a significant difference in the mean delta $(\Delta)$ reduction in body weight MISEM with CTRL ( $\mathrm{p}=0.000)$, MISEN with CTRL ( $\mathrm{p}=0.000)$, and MISEN with MISEM ( $\mathrm{p}=0.046)$.

\section{Discussions}

The results of this study show that there was an increase in the average body weight between pre-exercise and post-exercise on CTRL, while MISEM and MISEN showed a decrease in body weight between pre-exercise and post-exercise. The results of the Paired Samples T-Test analysis on CTRL showed that there was a significant difference in the average increase in body weight between pre-exercise and post-exercise, while the results of the Paired Samples T-Test analysis on MISEM and MISEN showed a decrease in body weight between pre-exercise. with post-exercise (Figure 1). The One-Way ANOVA test results show that there was no significant difference in the average pre-exercise body weight in all groups, while 4 weeks post-exercise and delta $(\Delta)$ showed a significant difference in the average body weight in all groups (Table 1). These results are in line with the research from Prasetya et al. (2018), which reported that Moderate-Intensity Exercise (MIE) for 4 weeks reduced body weight in mice.Likewise research conducted by Houdebine et al. (2019), which reported that swimming training significantly reduced body weight compared to the control group. Inoue et al. (2015) in their research reported that mild exercise (ME) and intense exercise (IE) significantly reduced body weight compared to controls (CONT). Research conducted by Kim et al. (2013) also reported that moderate-intensity exercise reduced weight loss compared to the control group. The weight loss in MISEM and MISEN may be due to the effects of physical exercise carried out for 4 weeks. During physical exercise there is a reduction and decrease in food intake as an energy source which causes the utilization of stored energy sources in the body increased, especially body fat stores, thereby causing weight loss.

Physical exercise has a positive effect in reducing the risk of overweight and obesity by reducing body fat stores. During physical exercise, the decrease in blood glucose results an insulin decrease and stimulates an increase in the hydrolysis of triglycerides into glycerol and Free Fatty Acid (FFA) as an energy source (Polak et al., 2008). In addition, exercise could stimulate an increase in growth hormone (GH) which has a role in metabolism to stimulate fat into an energy source (Chaves et al., 2013). Exercise performed at moderate intensity for 30 minutes can increase the production of FFA as an energy source (Karstoft et al., 2016), thereby potentially reducing visceral fat accumulation and body weight (Wewege et al., 2017). In addition, regular physical exercise also plays an important role in reducing the obesity by increasing energy output (Houdebine et al., 2019) mediated by the hormone irisin (Boström et al., 2012). Physical exercise stimulates the release of irisin through the activation of peroxisome proliferation-activated receptor coactivator-1 $\alpha$ (PGC-1 $\alpha$ ) (Boström et al., 2012) which can stimulate the expression of fibronectin type III domain-containing protein 5 (FNDC-5) (Fatouros, 2018) and proteolytic cleavage of the FNDC-5 membrane protein in skeletal muscle, resulting in the release of irisin into the blood circulation (Moreno-Navarrete et al., 2013). The release of irisin in the blood circulation induces the browning process in white adipose tissue by stimulating the expression of uncoupling protein-1 (UCP-1) via 
signaling p38 mitogen-activated protein kinase (p38-MAPK). Thus, it increased energy output and decreased fat accumulation, which can be a factor in weight loss in MISEM and MISEN (Fatouros, 2018; Perakakis et al., 2017; Boström et al., 2012).

The results of this study showed that there was an average increase in Lee's obesity index between preexercise and post-exercise on CTRL and MISEM, while MISEN showed a decrease in Lee's obesity index between pre-exercise and post-exercise. The results of the Paired Samples T-Test analysis on CTRL and MISEM showed that there was a significant difference in increasing Lee's obesity index between pre-exercise vs. post-exercise. Meanwhile, the results of the Paired Samples T-Test analysis at MISEN showed a decrease in Lee's obesity index between pre-exercise vs. post-exercise (Figure 2). The One-Way ANOVA test result showed that there was no significant difference in the average Lee's obesity index pre-exercise in all groups, while 4 weeks post-exercise and delta $(\Delta)$ showed significant differences in the average Lee's obesity index in all groups (Table 1). These results are in line with research conducted by Zein et al. (2017), which reported that slow-type interval training significantly lowered Lee's obesity index compared to controls. The decline in Lee's obesity index might be due to the physical exercise. During physical exercise there is an increase in lipolysis to fulfill energy needs, which lead to a decrease in fat deposits in the subcutaneous and visceral tissues. The reduction of fat deposition in the subcutaneous and visceral tissues leads to weight loss, resulting in a decrease of Lee's obesity index. The significant decrease in the value of Lee's obesity index in MISEN may also cause by a decrease in the size and number of adipocytes, resulting in a decrease in fat tissue mass (Scott et al., 2011). This condition was proved by a higher weight loss in MISEN than in MISEM and CTRL.

\section{Conclussions}

The results of this study showed that moderate-intensity swimming exercise at night and moderate-intensity swimming exercise in the morning performed 3 times per week for 4 weeks could reduced body weight compared to control without intervention. Moderate-intensity swimming exercise at night could decreased Lee's obesity index, while moderate-intensity swimming exercise in the morning and control without intervention actually increased Lee's obesity index. Thus, moderate-intensity swimming exercise in the night was more effective in reducing body weight and Lee's obesity index than moderate-intensity swimming exercise in the morning.

\section{References}

Adamson, B. C., Ensari, I., \& Motl, R. W. (2015). Effect of exercise on depressive symptoms in adults with neurologic disorders: a systematic review and meta-analysis. Archives of physical medicine and rehabilitation, 96(7), 1329-1338. https://doi.org/10.1016/j.apmr.2015.01.005.

Anandacoomarasamy, A., Caterson, I., Sambrook, P., Fransen, M., \& March, L. (2008). The impact of obesity on the musculoskeletal system. International journal of obesity (2005), 32(2), 211-222. https://doi.org/10.1038/sj.ijo.0803715.

Anstey, K. J., Cherbuin, N., Budge, M., \& Young, J. (2011). Body mass index in midlife and late-life as a risk factor for dementia: a meta-analysis of prospective studies. Obesity reviews : an official journal of the International Association for the Study of Obesity, 12(5), e426-e437. https://doi.org/10.1111/j.1467789X.2010.00825.x. 
Boström, P., Wu, J., Jedrychowski, M.P., Korde, A., Ye, L., Lo, J.C., Rasbach, K.A., Boström, E.A., Choi, J.H., Long, J.Z., Kajimura, S., Zingaretti, M.C., Vind, B.F., Tu, H., Cinti, S., Hojlund, K., Gygi, S.P. \& Spiegelman, B.M. (2012). A PGC1 $\alpha$-dependent myokine that drives browning of white fat and thermogenesis. Nature. 481(7382), 463-468. https://doi.org/10.1038/nature10777.A.

Bouchard, C., Antunes-Correa, L. M., Ashley, E. A., Franklin, N., Hwang, P. M., Mattsson, C. M., Negrao, C. E., Phillips, S. A., Sarzynski, M. A., Wang, P. Y., \& Wheeler, M. T. (2015). Personalized preventive medicine: genetics and the response to regular exercise in preventive interventions. Progress in cardiovascular diseases, 57(4), 337-346. https://doi.org/10.1016/j.pcad.2014.08.005.

Chaves, V. E., Júnior, F. M., \& Bertolini, G. L. (2013). The metabolic effects of growth hormone in adipose tissue. Endocrine, 44(2), 293-302. https://doi.org/10.1007/s12020-013-9904-3.

Chooi, Y. C., Ding, C., \& Magkos, F. (2019). The epidemiology of obesity. Metabolism: clinical and experimental, 92, 6-10. https://doi.org/10.1016/j.metabol.2018.09.005.

Crozier, J., Roig, M., Eng, J. J., MacKay-Lyons, M., Fung, J., Ploughman, M., Bailey, D. M., Sweet, S. N., Giacomantonio, N., Thiel, A., Trivino, M., \& Tang, A. (2018). High-Intensity Interval Training After Stroke: An Opportunity to Promote Functional Recovery, Cardiovascular Health, and Neuroplasticity. Neurorehabilitation and neural repair, 32(6-7), 543-556. https://doi.org/10.1177/1545968318766663.

Czernichow, S., Kengne, A. P., Stamatakis, E., Hamer, M., \& Batty, G. D. (2011). Body mass index, waist circumference and waist-hip ratio: which is the better discriminator of cardiovascular disease mortality risk?: evidence from an individual-participant meta-analysis of 82864 participants from nine cohort studies. Obesity reviews : an official journal of the International Association for the Study of Obesity, 12(9), 680687. https://doi.org/10.1111/j.1467-789X.2011.00879.x.

Driediger, M., Vanderloo, L. M., Truelove, S., Bruijns, B. A., \& Tucker, P. (2018). Encouraging kids to hop, skip, and jump: Emphasizing the need for higher-intensity physical activity in childcare. Journal of sport and health science, 7(3), 333-336. https://doi.org/10.1016/j.jshs.2018.03.003.

Fatouros, I.G. (2018). Is irisin the new player in exercise-induced adaptations or not? A 2017 update. Clinical Chemistry and Laboratory Medicine, 56(4), 525-548. https://doi.org/10.1515/cclm-2017-0674.

Febbraio M. A. (2017). Exercise metabolism in 2016: Health benefits of exercise - more than meets the eye!. Nature reviews. Endocrinology, 13(2), 72-74. https://doi.org/10.1038/nrendo.2016.218.

Guo, S., Huang, Y., Zhang, Y., Huang, H., Hong, S., \& Liu, T. (2020). Impacts of exercise interventions on different diseases and organ functions in mice. Journal of sport and health science, 9(1), 53-73. https://doi.org/10.1016/j.jshs.2019.07.004.

Hansen, D., Niebauer, J., Cornelissen, V., Barna, O., Neunhäuserer, D., Stettler, C., Tonoli, C., Greco, E., Fagard, R., Coninx, K., Vanhees, L., Piepoli, M. F., Pedretti, R., Ruiz, G. R., Corrà, U., Schmid, J. P., Davos, C. H., Edelmann, F., Abreu, A., Rauch, B. et al. (2018). Exercise Prescription in Patients with Different Combinations of Cardiovascular Disease Risk Factors: A Consensus Statement from the EXPERT Working Group. Sports medicine (Auckland, N.Z.), 48(8), 1781-1797. https://doi.org/10.1007/s40279-018-0930-4.

Haslan, M. A., Samsulrizal, N., Hashim, N., Zin, N., Shirazi, F. H., \& Goh, Y. M. (2021). Ficus deltoidea ameliorates biochemical, hormonal, and histomorphometric changes in letrozole-induced polycystic ovarian syndrome rats. BMC complementary medicine and therapies, 21(1), 291. https://doi.org/10.1186/s12906021-03452-6. 
Hatchard, T., Ting, J. J., \& Messier, C. (2014). Translating the impact of exercise on cognition: methodological issues in animal research. Behavioural brain research, 273, 177-188. https://doi.org/10.1016/j.bbr.2014.06.043.

Hjorth, M., \& Febbraio, M. A. (2018). Exercise as medicine for survivors of paediatric cancer. Nature reviews. Endocrinology, 14(9), 506-508. https://doi.org/10.1038/s41574-018-0065-6.

Hojman, P., Gehl, J., Christensen, J. F., \& Pedersen, B. K. (2018). Molecular Mechanisms Linking Exercise to Cancer Prevention and Treatment. Cell 10-21. https://doi.org/10.1016/j.cmet.2017.09.015.

Houdebine, L., D'Amico, D., Bastin, J., Chali, F., Desseille, C., Rumeau, V., Soukkari, J., Oudot, C., Rouquet, T., Bariohay, B., Roux, J., Sapaly, D., Weill, L., Lopes, P., Djouadi, F., Bezier, C., Charbonnier, F., \& Biondi, O. (2019). Low-Intensity Running and High-Intensity Swimming Exercises Differentially Improve Energy Metabolism in Mice With Mild Spinal Muscular Atrophy. Frontiers in Physiology, 10, 1258. https://doi.org/10.3389/fphys.2019.01258.

Inoue, K., Okamoto, M., Shibato, J., Lee, M. C., Matsui, T., Rakwal, R., \& Soya, H. (2015). Long-Term Mild, rather than Intense, Exercise Enhances Adult Hippocampal Neurogenesis and Greatly Changes the Transcriptomic Profile of the Hippocampus. PloS One, 10(6), e0128720. https://doi.org/10.1371/journal.pone.0128720.

Jakicic, J. M., Rogers, R. J., Davis, K. K., \& Collins, K. A. (2018). Role of Physical Activity and Exercise in Treating Patients with Overweight and Obesity. Clinical chemistry, 64(1), 99-107. https://doi.org/10.1373/clinchem.2017.272443.

Karstoft, K., Wallis, G. A., Pedersen, B. K., \& Solomon, T. P. (2016). The effects of interval- vs. continuous exercise on excess post-exercise oxygen consumption and substrate oxidation rates in subjects with type 2 diabetes. Metabolism: clinical and experimental, 65(9), 1316-1325. https://doi.org/10.1016/j.metabol.2016.05.017.

Kim, D. H., Kim, S. H., Kim, W. H., \& Moon, C. R. (2013). The effects of treadmill exercise on expression of UCP-2 of brown adipose tissue and TNF- $\alpha$ of soleus muscle in obese Zucker rats. Journal of Exercise Nutrition \& Biochemistry, 17(4), 199-207. https://doi.org/10.5717/jenb.2013.17.4.199.

Kostrzewa, E., \& Kas, M. J. (2014). The use of mouse models to unravel genetic architecture of physical activity: a review. Genes, brain, and behavior, 13(1), 87-103. https://doi.org/10.1111/gbb.12091.

Kwak, J. J., Yook, J. S., \& Ha, M. S. (2020). Potential Biomarkers of Peripheral and Central Fatigue in HighIntensity Trained Athletes at High-Temperature: A Pilot Study with Momordica charantia (Bitter Melon). Journal of immunology research, 2020: 4768390. https://doi.org/10.1155/2020/4768390.

Lauby-Secretan, B., Scoccianti, C., Loomis, D., Grosse, Y., Bianchini, F., Straif, K., \& International Agency for Research on Cancer Handbook Working Group (2016). Body Fatness and Cancer--Viewpoint of the IARC Working Group. The New England journal of medicine, 375(8), 794-798. https://doi.org/10.1056/NEJMsr1606602.

Lü, J., Fu, W., \& Liu, Y. (2016). Physical activity and cognitive function among older adults in China: A systematic review. Journal of sport and health science, 5(3), 287-296. https://doi.org/10.1016/j.jshs.2016.07.003. 
McKeough, Z. J., Velloso, M., Lima, V. P., \& Alison, J. A. (2016). Upper limb exercise training for COPD. The $\begin{array}{llll}\text { Cochrane database } & \text { of }\end{array}$ https://doi.org/10.1002/14651858.CD011434.pub2.

Mo, C., Hannan, A. J., \& Renoir, T. (2015). Environmental factors as modulators of neurodegeneration: insights from gene-environment interactions in Huntington's disease. Neuroscience and biobehavioral reviews, 52, 178-192. https://doi.org/10.1016/j.neubiorev.2015.03.003.

Mo, C., Renoir, T., \& Hannan, A. J. (2016). What's wrong with my mouse cage? Methodological considerations for modeling lifestyle factors and gene-environment interactions in mice. Journal of neuroscience methods, 265, 99-108. https://doi.org/10.1016/j.jneumeth.2015.08.008.

Moreno-Navarrete, J.M., Ortega, F., Serrano, M., Guerra, E., Pardo, G., Tinahones, F., Ricart, W. \& FernandezReal, J.M. (2013). Irisin is expressed and produced by human muscle and adipose tissue in association with obesity and insulin resistance. Journal of Clinical Endocrinology and Metabolism, 98(4), 769-778. https://doi.org/10.1210/jc.2012-2749.

Overall, R. W., Walker, T. L., Fischer, T. J., Brandt, M. D., \& Kempermann, G. (2016). Different Mechanisms Must Be Considered to Explain the Increase in Hippocampal Neural Precursor Cell Proliferation by Physical Activity. Frontiers in neuroscience, 10, 362. https://doi.org/10.3389/fnins.2016.00362.

Patten, A. R., Yau, S. Y., Fontaine, C. J., Meconi, A., Wortman, R. C., \& Christie, B. R. (2015). The Benefits of Exercise on Structural and Functional Plasticity in the Rodent Hippocampus of Different Disease Models. Brain plasticity (Amsterdam, Netherlands), 1(1), 97-127. https://doi.org/10.3233/BPL-150016.

Perakakis, N., Triantafyllou, G.A., Fernández-Real, J.M., Huh, J.Y., Park, K.H., Seufert, J. and Mantzoros, C.S., 2017. Physiology and role of irisin in glucose homeostasis. Nature Reviews Endocrinology, 13(6), 324-337. https://doi.org/10.1038/nrendo.2016.221.

Polak, J., Bajzova, M., \& Stich, V. (2008). Effect of exercise on lipolysis in adipose tissue. Future Lipidology, 3(5), 557-572. https://doi.org/10.2217/17460875.3.5.557.

Pranoto, A., Wahyudi, E., Prasetya, R.E., Fauziyah, S., Kinanti, R.G., Sugiharto, S., \& Rejeki, P.S. (2020). High intensity exercise increases brain derived neurotrophic factor expression and number of hippocampal neurons in rats. Comparative Exercise Physiology, 16(4), 325-332. https://doi.org/10.3920/CEP190063.

Prasetya, R.E., Umijati, S., \& Rejeki, P.S. (2018). Effect of Moderate Intensity Exercise on Body Weight and Blood Estrogen Level Ovariectomized Mice. Majalah Kedokteran Bandung, 50 (3): 147 - 151. https://doi.org/10.15395/mkb.v50n3.1368.

Rejeki, P.S., Utami, D.M., Izzatunnisa, N., Pranoto,A., Sukarno, D.A., and Fasitasari, M. (2021). High-fat diet decreases serum TNF-alpha and breast tumor area on benzopyrene induced mice (Mus musculus). CMU J. Nat. Sci. 20(4): e2021089. https://doi.org/10.12982/CMUJNS.2021.089.

Scott, J. P., Sale, C., Greeves, J. P., Casey, A., Dutton, J., \& Fraser, W. D. (2011). Effect of exercise intensity on the cytokine response to an acute bout of running. Medicine and science in sports and exercise, 43(12), 22972306. https://doi.org/10.1249/MSS.0b013e31822113a9. 
Singh, G. M., Danaei, G., Farzadfar, F., Stevens, G. A., Woodward, M., Wormser, D., Kaptoge, S., Whitlock, G., Qiao, Q., Lewington, S., Di Angelantonio, E., Vander Hoorn, S., Lawes, C. M., Ali, M. K., Mozaffarian, D., Ezzati, M., Global Burden of Metabolic Risk Factors of Chronic Diseases Collaborating Group; Asia-Pacific Cohort Studies Collaboration (APCSC), Diabetes Epidemiology: Collaborative analysis of Diagnostic criteria in Europe (DECODE), Emerging Risk Factor Collaboration (ERFC), \& Prospective Studies Collaboration (PSC) (2013). The age-specific quantitative effects of metabolic risk factors on cardiovascular diseases and diabetes: a pooled analysis. PloS One, 8(7), e65174. https://doi.org/10.1371/journal.pone.0065174.

Shepherd, A., Zhang, T. D., Zeleznikow-Johnston, A. M., Hannan, A. J., \& Burrows, E. L. (2018). Transgenic Mouse Models as Tools for Understanding How Increased Cognitive and Physical Stimulation Can Improve Cognition in Alzheimer's Disease. Brain plasticity (Amsterdam, Netherlands), 4(1), 127-150. https://doi.org/10.3233/BPL-180076.

Wewege, M., van den Berg, R., Ward, R. E., \& Keech, A. (2017). The effects of high-intensity interval training vs. moderate-intensity continuous training on body composition in overweight and obese adults: a systematic review and meta-analysis. Obesity reviews : an official journal of the International Association for the Study of Obesity, 18(6), 635-646. https://doi.org/10.1111/obr.12532.

Widiatmaja, D., Lutvyani, A., Sari, D., Kurniasari, H., Meiliana, I., Fasitasari, M., Yamaoka, Y. \& Rejeki, P.S. (2021). The effect of long-term ketogenic diet on serum adiponectin and insulin-like growth factor-1 levels in mice. Journal of Basic and Clinical Physiology and Pharmacology. https://doi.org/10.1515/jbcpp-2021$\underline{0287}$.

Wierzba, T. H., Olek, R. A., Fedeli, D., \& Falcioni, G. (2006). Lymphocyte DNA damage in rats challenged with a single bout of strenuous exercise. Journal of physiology and pharmacology : an official journal of the Polish Physiological Society, 57(10): 115-131.

Zanuso, S., Sacchetti, M., Sundberg, C. J., Orlando, G., Benvenuti, P., \& Balducci, S. (2017). Exercise in type 2 diabetes: genetic, metabolic and neuromuscular adaptations. A review of the evidence. British journal of sports medicine, 51(21), 1533-1538. https://doi.org/10.1136/bjsports-2016-096724.

Zein, E.M., Lubis, V.M.T., \& Purba, A. (2017). Efek Interval Training terhadap Indeks Lee, Kadar Adiponektin, dan IL-6 pada Tikus Model Obesitas. Majalah Kedokteran Bandung, 49(1), 15-21. http://dx.doi.org/10.15395/mkb.v49n1.983.

Zhang, H. J., He, J., Pan, L. L., Ma, Z. M., Han, C. K., Chen, C. S., Chen, Z., Han, H. W., Chen, S., Sun, Q., Zhang, J. F., Li, Z. B., Yang, S. Y., Li, X. J., \& Li, X. Y. (2016). Effects of Moderate and Vigorous Exercise on Nonalcoholic Fatty Liver Disease: A Randomized Clinical Trial. JAMA internal medicine, 176(8), 10741082. https://doi.org/10.1001/jamainternmed.2016.3202. 